\title{
Prognostic Effect of Long-Axis Left Ventricular Dysfunction and B-Type Natriuretic Peptide Levels in Asymptomatic Aortic Stenosis
}

\author{
Patrizio Lancellotti, MD, $\mathrm{PhD}^{\mathrm{a}, *}$, Marie Moonen, $\mathrm{MD}^{\mathrm{a}}$, Julien Magne, $\mathrm{PhD}^{\mathrm{a}}$, Kim O'Connor, $\mathrm{MD}^{\mathrm{a}}$, \\ Bernard Cosyns, $\mathrm{MD}^{\mathrm{b}}$, Emilio Attena, $\mathrm{MD}^{\mathrm{a}}$, Erwan Donal, $\mathrm{MD}^{\mathrm{c}}$, and Luc Pierard, $\mathrm{MD}, \mathrm{PhD}^{\mathrm{a}}$
}

\begin{abstract}
In aortic stenosis (AS), the increased afterload results in progressive structural and functional changes that precede the development of symptoms. We hypothesized that the detection of abnormalities in left ventricular long-axis function could identify patients with asymptomatic AS at increased risk of events. We prospectively examined the outcome of 126 patients with asymptomatic AS who underwent a comprehensive echocardiographic examination, including tissue Doppler imaging. B-type natriuretic peptide (BNP) was measured in all patients. During a median follow-up period of $20.3 \pm 17.8$ months, 6 patients died, 8 developed symptoms but did not undergo surgery, and 48 underwent aortic valve replacement. On multivariate Cox regression analysis, the parameters associated with the predefined outcome were gender $(p=0.048)$, left atrial area index $(p=0.011)$, systolic annular velocity $(\mathrm{p}=0.016), \mathrm{E} / \mathrm{Ea}$ ratio $(\mathrm{p}=0.024)$, late diastolic annular velocity $(\mathrm{p}=$ $0.023)$, and $\mathrm{BNP}(\mathrm{p}=0.012)$. Using receiver operating characteristics curve analysis, a left atrial area index of $\geq 12.4 \mathrm{~cm}^{2} / \mathrm{m}^{2}$, systolic annular velocity of $\leq 4.5 \mathrm{~cm} / \mathrm{s}$, E/Ea ratio $>13.8$, late diastolic annular velocity of $\leq 9 \mathrm{~cm} / \mathrm{s}$, and BNP of $\geq 61 \mathrm{pg} / \mathrm{ml}$ were identified as the best cutoff values to predict events. In conclusion, in asymptomatic AS, tissue Doppler imaging and BNP measurements provide prognostic information beyond that from clinical and conventional echocardiographic parameters. (C) 2010 Elsevier Inc. All rights reserved. (Am J Cardiol 2010;105:383-388)
\end{abstract}

Aortic valve stenosis (AS) is the most common valvular disease and has become the most common cardiovascular disease, after coronary artery disease and hypertension, in developed countries. ${ }^{1}$ AS is characterized by a long asymptomatic phase, lasting several decades, during which outflow obstruction progressively develops. ${ }^{2}$ Aortic valve replacement is the sole effective therapy for symptomatic patients. In contrast, the management of asymptomatic AS remains controversial. ${ }^{3,4}$ In these patients, the chronically increased afterload results in progressive left ventricular (LV) myocardial hypertrophy and interstitial fibrosis, diastolic dysfunction, elevated left atrial pressures, dilation of the left atrium, and, eventually, intrinsic myocardial dysfunction. ${ }^{5}$ These structural and functional changes precede symptom development, predict changes in clinical status, and trigger B-type natriuretic peptide (BNP) release. ${ }^{6,7}$ In $\mathrm{AS}$, the BNP level correlates with the valve area, diastolic function, functional status, and symptomatic deterioration and might improve risk stratification. ${ }^{8-11}$ Tissue Doppler measurement of mitral annular velocities is a sensitive method for the detection of early abnormalities in LV longaxis function and improves the assessment of LV diastolic function. ${ }^{12}$ In asymptomatic AS, the incremental prognostic value of tissue Doppler imaging and BNP measurement

\footnotetext{
${ }^{a}$ Department of Cardiology, University Hospital Sart Tilman, Liège, Belgium; ' $\mathrm{CHIREC}$, Braine l'Alleud, Belgium; and ${ }^{\mathrm{c}} \mathrm{CHU}$ de Ponchaillou, Rennes, France. Manuscript received July 2, 2009; revised manuscript received and accepted September 8, 2009.

*Corresponding author: Tel: (+32) 4-366-7194; fax: $(+32)$ 4-3667195.

E-mail address: plancellotti@ chu.ulg.ac.be (P. Lancellotti).
}

compared with validated parameters has never been investigated. The present study was undertaken to prospectively assess the comparative usefulness in predicting the clinical outcomes of long-axis function and BNP level in a series of patients with asymptomatic severe AS.

\section{Methods}

Asymptomatic patients with severe AS were prospectively screened from our echocardiographic laboratory for inclusion in the present study. All the patients met the following criteria: (1) moderate to severe AS, as defined by an aortic valve area of $\leq 1.2 \mathrm{~cm}^{2}$; (2) no symptoms according to a careful history taken by the referring physician; (3) normal LV ejection fraction ( $\geq 55 \%$ ), as calculated by 2 -dimensional echocardiography; (4) no more than mild associated cardiac valve lesions; (5) sinus rhythm; and (6) serum creatinine $<16 \mathrm{mg} / \mathrm{L}$. A total of 126 patients met these criteria. The relevant institutional review boards approved the protocol, and all patients gave written informed consent.

A comprehensive Doppler echocardiographic study, including M-mode, 2-dimensional echocardiography, color Doppler, and pulsed-wave and continuous-wave Doppler measurements was performed, in all patients using a VIVID 7 ultrasound machine (General Electric Healthcare, Little Chalfont, United Kingdom). The images were stored on a dedicated workstation for off-line analysis. For each measurement, $\geq 2$ cardiac cycles were averaged. Continuouswave Doppler was used to measure the aortic transvalvular maximal velocities; the peak and mean gradients were calculated using the simplified Bernoulli equation. The aortic valve area was calculated from the continuity equation. ${ }^{13}$ 
Table 1

Patient characteristics

\begin{tabular}{|c|c|c|c|c|c|}
\hline \multirow[t]{2}{*}{ Variable } & \multirow{2}{*}{$\begin{array}{c}\text { No Events } \\
(\mathrm{n}=64,51 \%)\end{array}$} & \multirow{2}{*}{$\begin{array}{c}\text { Events } \\
(\mathrm{n}=62,49 \%)\end{array}$} & \multirow{2}{*}{$\frac{\text { Univariate }}{\mathrm{p} \text { Value }}$} & \multicolumn{2}{|r|}{ Multivariate } \\
\hline & & & & p Value & Hazard Ratio $(95 \% \mathrm{CI})$ \\
\hline Age (years) & $68 \pm 10$ & $67 \pm 12$ & 0.51 & - & - \\
\hline Women & $16(25 \%)$ & $35(56 \%)$ & 0.00024 & $0.048^{*}$ & $0.53(0.28-0.99)^{*}$ \\
\hline Hypertension & $29(43 \%)$ & $32(52 \%)$ & 0.51 & - & - \\
\hline Diabetes mellitus & $12(19 \%)$ & $12(19 \%)$ & 0.97 & - & - \\
\hline Hypercholesterolemia & $28(44 \%)$ & $26(42 \%)$ & 0.34 & - & - \\
\hline Systolic arterial pressure $(\mathrm{mm} \mathrm{Hg})$ & $144 \pm 18$ & $141 \pm 19$ & 0.55 & - & - \\
\hline B-type natriuretic peptide $(\mathrm{pg} / \mathrm{ml})$ & $39.9 \pm 27.3$ & $166 \pm 237$ & $<0.0001$ & $0.012 *$ & $1.001(1-1.003)^{*}$ \\
\hline Serum creatinine $(\mathrm{mg} / \mathrm{l})$ & $8.2 \pm 1.8$ & $8.7 \pm 1.7$ & 0.14 & - & - \\
\hline Abnormal response to exercise & $6(9)$ & $26(42)$ & 0.007 & 0.88 & $0.95(0.49-1.8)$ \\
\hline Aortic valve area $\left(\mathrm{cm}^{2}\right)$ & $0.86 \pm 0.13$ & $0.79 \pm 0.16$ & 0.05 & 0.80 & $1.49(0.06-34)$ \\
\hline Peak aortic velocity $(\mathrm{m} / \mathrm{s})$ & $4.03 \pm 0.55$ & $4.35 \pm 0.58$ & 0.0013 & 0.58 & $1.31(0.5-3.4)$ \\
\hline Aortic peak pressure gradient (mm Hg) & $69.7 \pm 19.7$ & $77 \pm 21$ & 0.01 & - & - \\
\hline Aortic mean pressure gradient $(\mathrm{mm} \mathrm{Hg})$ & $42.4 \pm 13.4$ & $46.7 \pm 13$ & 0.046 & 0.32 & $1.02(0.9-1.06)$ \\
\hline Left ventricular mass $(\mathrm{g})$ & $174 \pm 86$ & $169 \pm 67$ & 0.85 & - & - \\
\hline Left ventricular end-diastolic volume $(\mathrm{ml})$ & $92.8 \pm 26.5$ & $96.9 \pm 30.3$ & 0.94 & - & - \\
\hline Left ventricular end-systolic volume (ml) & $32.2 \pm 14.2$ & $32.5 \pm 13$ & 0.91 & - & - \\
\hline Left ventricular ejection fraction (\%) & $65.8 \pm 7.4$ & $67.4 \pm 7.5$ & 0.52 & - & - \\
\hline Left atrial area index $\left(\mathrm{cm}^{2} / \mathrm{m}^{2}\right)$ & $10.3 \pm 2.1$ & $14.8 \pm 3.4$ & $<0.0001$ & $0.011 *$ & $1.06(1.01-1.11)^{*}$ \\
\hline Mitral early diastolic filling wave $(\mathrm{cm} / \mathrm{s})$ & $77 \pm 24$ & $83 \pm 26$ & 0.12 & - & - \\
\hline Mitral late diastolic filling wave $(\mathrm{cm} / \mathrm{s})$ & $87 \pm 29$ & $89 \pm 28$ & 0.29 & - & - \\
\hline Mitral early/late diastolic filling ratio & $0.92 \pm 0.32$ & $0.99 \pm 0.48$ & 0.53 & - & - \\
\hline Mitral early diastolic filling wave deceleration time (ms) & $219 \pm 78$ & $237 \pm 97$ & 0.34 & - & - \\
\hline Peak systolic velocity $(\mathrm{cm} / \mathrm{s})$ & $5.2 \pm 0.9$ & $3.6 \pm 1.6$ & $<0.0001$ & $0.016^{*}$ & $0.73(0.57-0.94)^{*}$ \\
\hline Peak early diastolic annular velocity $(\mathrm{cm} / \mathrm{s})$ & $9.95 \pm 1.7$ & $7.9 \pm 1.8$ & 0.025 & 0.91 & $1.01(0.84-1.2)$ \\
\hline Peak late diastolic annular velocity $(\mathrm{cm} / \mathrm{s})$ & $8.7 \pm 2$ & $7.6 \pm 2.1$ & $<0.0001$ & $0.023^{*}$ & $0.81(0.67-0.97)^{*}$ \\
\hline Early diastolic filling/annular velocity (average annuli) & $10 \pm 3.3$ & $13.5 \pm 6.6$ & 0.009 & $0.024 *$ & $0.94(0.88-0.99)^{*}$ \\
\hline
\end{tabular}

* Parameters selected on the multivariate Cox regression analysis.

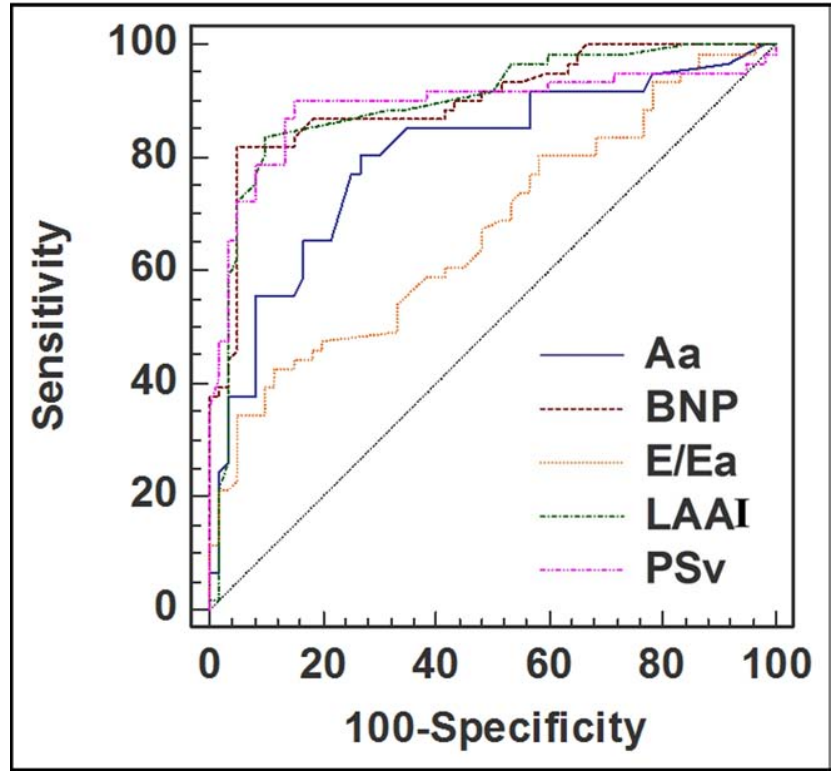

Figure 1. Receiver operating characteristics curves of predictors of outcome. $\mathrm{Aa}=$ late diastolic annular velocity; LAAI = left atrial area index; $\mathrm{PSv}=$ peak systolic velocity.

The LV end-diastolic and end-systolic volumes and ejection fraction were measured using the bi-apical Simpson disk method. ${ }^{14}$ The left atrial area was obtained by planimetry in 2 end-systolic frames of the apical 4-chamber view. Color
Table 2

Area under curve, sensitivity, specificity, and optimal cutoff values of significant variables for predicting outcome

\begin{tabular}{lcccc}
\hline Data at Inclusion & $\begin{array}{c}\text { Cutoff } \\
\text { Value }\end{array}$ & $\begin{array}{c}\text { Area Under } \\
\text { Curve }\end{array}$ & Sensitivity & Specificity \\
\hline $\begin{array}{c}\text { Left atrial area index } \\
\left(\mathrm{cm}^{2} / \mathrm{m}^{2}\right)\end{array}$ & $\geq 12.4$ & 0.90 & $83.9 \%$ & $90.6 \%$ \\
$\begin{array}{c}\text { Peak systolic velocity } \\
(\mathrm{cm} / \mathrm{s})\end{array}$ & $\leq 4.5$ & 0.87 & $88.7 \%$ & $82.8 \%$ \\
$\begin{array}{l}\text { Peak Aa velocity (cm/s) } \\
\text { Early diastolic filling/ } \\
\text { annular velocity }\end{array}$ & $\leq 13.8$ & 0.81 & $80.6 \%$ & $75 \%$ \\
$\begin{array}{c}\text { B-type natriuretic } \\
\text { peptide (pg/ml) }\end{array}$ & $\geq 61$ & 0.89 & $42 \%$ & $88 \%$ \\
\hline
\end{tabular}

tissue Doppler imaging was performed in the apical views ( 2 and 4 chamber) to assess longitudinal myocardial function (frame rate $\geq 115 / \mathrm{s}$ ). ${ }^{14}$ Off-line peak systolic velocities obtained at the level of the septal, lateral, inferior, and anterior mitral annulus were measured separately and then averaged. An effort was made to align each of the LV walls as near to $0^{\circ}$ as possible to the long-axis motion. For diastolic function, the peak velocities of early (E) and late (A) diastolic filling, E/A ratio, deceleration time, and isovolumic relaxation time were derived from Doppler recordings of LV inflow. Using pulsed-wave tissue Doppler, the peak velocities during early (Ea) and late (Aa) diastole obtained at the level of the septal and lateral mitral annulus 

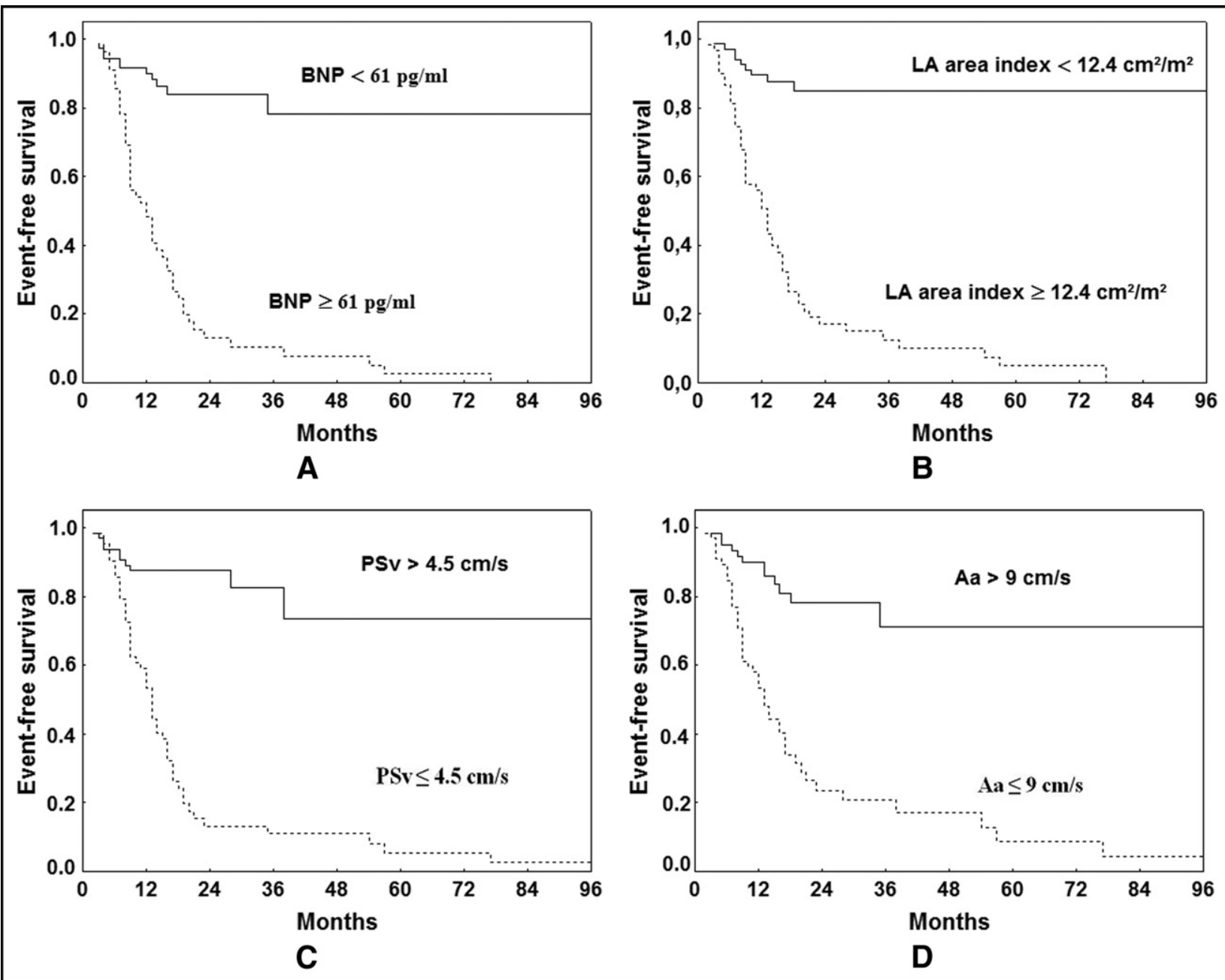

Figure 2. The four figures represent the Kaplan-Meier event-free survival curves according the following categorical variables which were selected in the multivariate model to predict the outcome in asymptomatic patients with AS. (A) BNP: B-Type Natriuretic Peptide; (B) LA: left atrial area; $(C)$ PSv: peak systolic velocity; $(D)$ Aa: late diastolic annular velocity.

were measured separately and then averaged. The E/Ea ratio was then calculated.

Venous blood samples for BNP measurement were drawn before echocardiography, after 10 minutes of supine rest. Chilled ethylenediaminetetraacetic acid tubes were centrifuged immediately at $4,000 \mathrm{rpm}\left(4^{\circ} \mathrm{C}\right)$ for 15 minutes. Separated plasma samples were processed by immunofluorescence assay (Biosite, Beckman Coulter, San Diego, California). The inter- and intra-assay variation was 5\% and $4 \%$, respectively. The assay detection limit was $1 \mathrm{pg} / \mathrm{ml}$.

Symptom-limited graded bicycle exercise tests were performed at inclusion for all patients. After an initial workload of $25 \mathrm{~W}$ maintained for 2 minutes, the load was increased by steps of $25 \mathrm{~W}$ every 2 minutes. The exercise test was interrupted when the age-related maximum heart rate was reached or if symptoms, hypotension, or significant ventricular arrhythmias developed. The test was considered abnormal if the patient presented with $\geq 1$ of the following criteria: (1) angina, (2) evidence of dyspnea, (3) dizziness, (4) syncope or near-syncope, (5) and increase in systolic blood pressure during exercise of $<20 \mathrm{~mm} \mathrm{Hg}$ or a decrease in blood pressure, and (6) ventricular tachycardia or $>4$ pre- mature ventricular complexes in a row. Because the present study was conducted before the official recommendations of 2007, the results of the exercise test, even when abnormal, did not affect patient treatment.

Follow-up information was obtained from interviews with the patients, their relatives, or their physicians every 6 to 12 months, according to the guidelines. Particular care was taken to obtain information regarding the development of symptoms, eventual aortic valve replacement, and death. The clinical management was determined independently by the patient's personal physician using all information available. The combined end point included the onset of symptoms (angina, dyspnea, syncope, heart failure), cardiac-related death, and the need for aortic valve replacement.

Continuous variables are expressed as the mean $\pm \mathrm{SD}$, unless otherwise specified. Group comparisons for categorical variables were obtained using the chi-square test and for continuous variables with 1-way analysis of variance. Analysis was performed by censoring follow-up data at cardiac surgery, if eventually performed. To detect independent predictors of events, a multivariate Cox proportional hazards regression procedure was used to compare the patients 


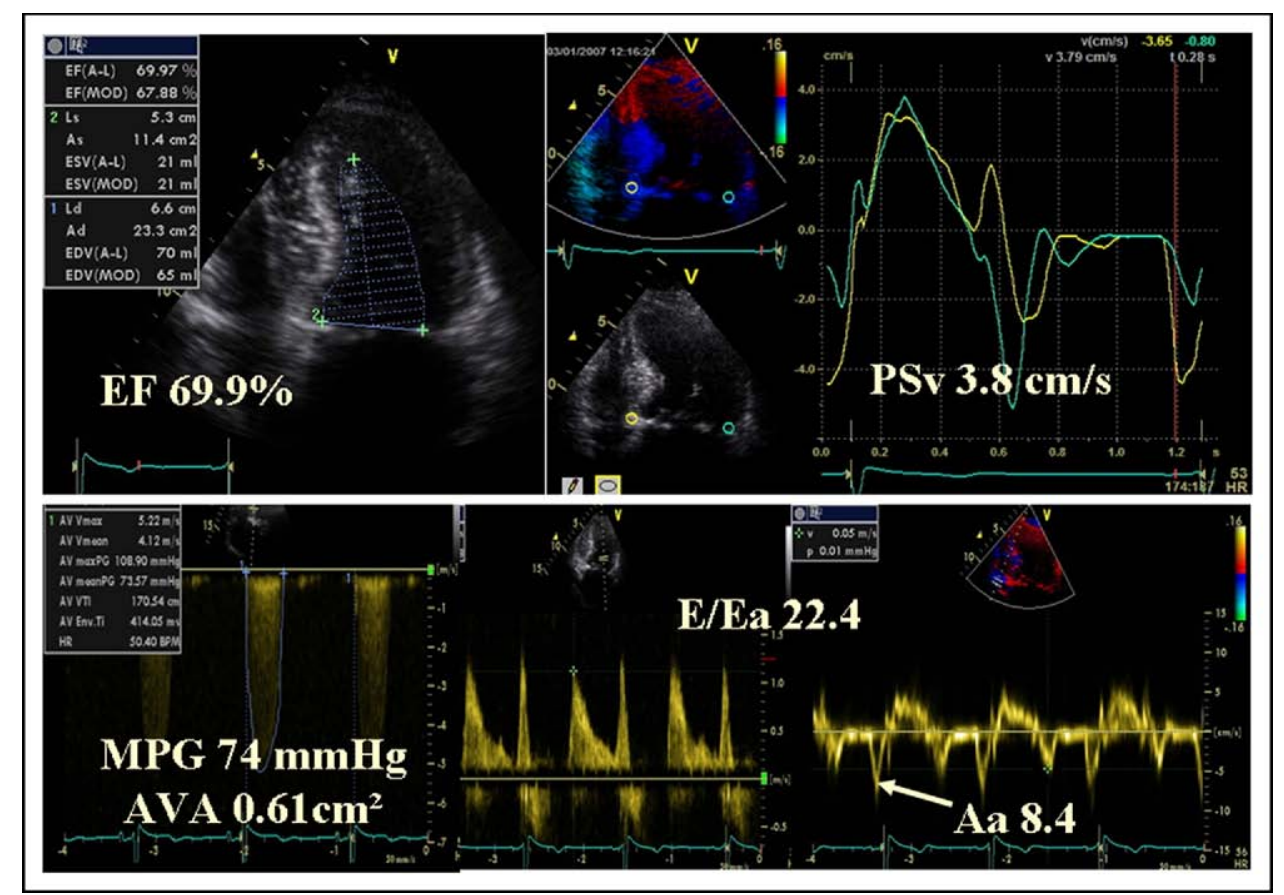

Figure 3. Example of patient with severe AS and impaired long-axis function. Aa = late diastolic annular velocity; $\mathrm{AVA}=\mathrm{aortic}$ valve area; $\mathrm{EF}=$ ejection fraction; MPG = mean transaortic pressure gradient; PSv = peak systolic velocity.

who remained asymptomatic during follow-up and those who experienced an event (STATISTICA, version 7, Statsoft, France). All clinically relevant variables with $\mathrm{p}<0.10$ were included in the multivariate model. p Values $<0.05$ were considered significant. Receiver operating characteristic curve analysis was performed to determine the cutoff values that best distinguished the issue (area under the curve). Survival curves were established using the KaplanMeier method, and statistical significance was determined using the log-rank test.

\section{Results}

The mean patient age was $67 \pm 10$ years (range 41 to $84)$. From the patient history and echocardiographic analysis findings, the suspected origin of AS was calcification of a trileaflet $(n=104)$, bicuspid $(n=15)$, rheumatic disease (commissural fusion and calcification most prominent along the edges of the cusps on echocardiography; $n=5$ ), and undetermined $(\mathrm{n}=2)$. The aortic valve area range was 0.38 to $1.2 \mathrm{~cm}^{2}$ (mean $0.82 \pm 0.15$ ), and the peak aortic pressure gradient was $77 \pm 21 \mathrm{~mm} \mathrm{Hg}$. The mean aortic pressure gradient was 26 to $86 \mathrm{~mm} \mathrm{Hg}$ (mean $45 \pm 14$ ). The mean LV ejection fraction was $67 \pm 7 \%$ (range $55 \%$ to $84 \%$ ), and the mean peak annular systolic velocity was $4.5 \pm 1.5 \mathrm{~cm} / \mathrm{s}$ (range 0.84 to 9 ). The mean BNP level was $102 \pm 178$ $\mathrm{pg} / \mathrm{ml}$ (range 5 to 1,500). At inclusion, the exercise test findings were abnormal (dyspnea in 20, decrease or increase in systolic blood pressure during exercise of $<20 \mathrm{~mm} \mathrm{Hg}$ in 6 , and combined parameters in 6) in 32 patients $(25 \%)$. During a median follow-up period of $20.3 \pm 18.7$ months (interquartile range 9 to 22 ), the predefined end point occurred in 62 patients. Of the 62 patients, 6 patients died from cardiovascular causes: 3 suddenly and 3 from progres- sive heart failure. Aortic valve replacement was required for the development of symptoms in 34 patients, new-onset atrial fibrillation in 1, newly positive exercise test findings in 7 , and equivocal symptoms in 6 . Finally, 8 patients developed symptoms but refused to undergo surgery.

The clinical and echocardiographic characteristics of the patients who remained asymptomatic or experienced an event are listed in Table 1. No clinical data, except female gender, allowed the distinction between the 2 groups. Patients who experienced an end point had a smaller aortic valve area, lower tissue Doppler annular systolic and diastolic velocities, and a greater E/Ea ratio, left atrial area, and BNP level. The response to exercise was more often abnormal in these patients. On multivariate Cox regression analysis, the parameters independently associated with the predefined composite outcome were gender, left atrial area index, systolic annular velocity, E/Ea, late diastolic annular velocity (Aa), and BNP level (Figure 1, Table 2). Figure 2 shows the survival curves for categorical variables, and Figure 3 shows an example of a patient with impaired long-axis function. In the subgroup of patients with a normal response to exercise, except for the $\mathrm{E} / \mathrm{Ea}$, the other parameters remained independently associated with the outcome.

\section{Discussion}

The decision to perform surgery on asymptomatic patients with AS remains controversial. ${ }^{3,4}$ The immediate risks of surgery are often weighed against the later risk of events without intervention. ${ }^{15}$ Therefore, reliable risk stratification is clinically important. ${ }^{16-18}$ In the present prospective study, we report, for the first time, the added prognostic value of tissue Doppler imaging and BNP measurement compared to 
the classical clinical and echocardiographic parameters in a prospective series of patients with asymptomatic moderate to severe AS. Patients, particularly females, with impaired long-axis function and increased BNP levels were at increased risk of untoward events.

In AS, the chronically increased afterload results in progressive LV remodeling and myocardial hypertrophy. ${ }^{19} \mathrm{Al}-$ though the increase in LV wall thickness is a compensatory mechanism that reduces systolic wall stress, it can result in impaired LV relaxation, reduced LV compliance, and increased metabolic demands. The ability of the LV to adequately fill under normal pressures is thus altered, and the LV diastolic pressure increases. As a result, LV filling becomes more dependent on the atrial contribution. In the advanced stage of the disease, the chronic increase in LV filling pressure is accompanied by progressive left atrial enlargement and dysfunction. ${ }^{20}$ Elevated LV diastolic pressure also limits the coronary perfusion pressure with a reduction of the subendocardial coronary flow reserve, which leads to myocardial ischemia even in the absence of significant coronary artery disease. ${ }^{21}$ Despite appropriate hypertrophy and accumulation of collagen in the subendocardial region, the LV ejection fraction can be classically maintained within the normal range for years. ${ }^{22}$ This reflects the preserved contribution of radial thickening to LV function. In contrast, the LV longitudinal function will be impaired because of subendocardial dysfunction. Initially, subendocardial dysfunction might normalize after aortic valve surgery. ${ }^{23}$

In the present study, except for female gender, neither the clinical findings (i.e., age, risk factors, exercise test) nor standard echocardiographic parameters (i.e., severity of stenosis, LV mass, LV volume, LV ejection fraction, extent of valve calcification) emerged as independent predictors of outcome. However, the prognostic effect of these factors was probably weakened by the inclusion of almost specifically elderly patients (in which the positive predictive value of exercise testing is limited) and the analysis of more powerful predictors of outcome such as BNP level and tissue Doppler parameters. ${ }^{24,25}$ In these patients, the increased release of BNP from the ventricles could reflect the substantial gender differences in the LV adaptive responses to $\mathrm{AS}^{26}$ BNP has been shown to be associated with the prognosis in several cardiovascular diseases such as AS..$^{7-11}$ In heart failure, the predictive value of BNP seems to be greater in women than in men. ${ }^{27}$ Our results have confirmed the strong prognostic value of BNP in a cohort of patients with asymptomatic AS.

The current guidelines consider surgery as reasonable in patients with asymptomatic severe $\mathrm{AS}$ and reduced $\mathrm{LV}$ ejection fraction $(<50 \%),{ }^{3,4}$ However, the LV ejection fraction is often normal in these patients. In contrast to this crude estimate of the LV systolic function, tissue Doppler imaging is superior for detecting subtle changes in myocardial function. ${ }^{12}$ Measurements of myocardial systolic annular velocities reflect longitudinal motion owing to the longitudinally directed fibers, which are mainly located in the subendocardium and subepicardium. When the velocities are averaged from the 4 regions of the annulus, they reflect the global long-axis function. In patients with asymptomatic AS, impaired subendocardial function has been shown to be associated with impaired exercise tolerance and changes in symptomatic status during short-term follow-up. ${ }^{6,22}$ Our results have extended these preliminary data by showing that the decrease in long-axis function can identify a subset of patients with moderate to severe asymptomatic AS at greater risk of developing cardiac events.

In the present study, we found that the left atrial area, late diastolic annular velocity (Aa), and E/Ea ratio were strong independent predictors of outcome. The left atrial size reflects the chronicity of diastolic burden. ${ }^{28}$ A value of $\geq 12.4$ $\mathrm{cm}^{2} / \mathrm{m}^{2}$ provided high predictive accuracy for cardiac events. The late diastolic annular velocity reliably quantifies the left atrial contribution to LV filling. In these patients, the left atrial booster pump function has a crucial role in counteracting the increased LV end-diastolic pressure and the delayed LV untwisting to maintain optimal cardiac output. ${ }^{29}$ A reduction in left atrial function might thus favor clinical deterioration. In our population, a late diastolic annular velocity of $\leq 9 \mathrm{~cm} / \mathrm{s}$ was associated with an excess risk of death, symptoms, or surgery. An increased E/Ea ratio, an estimate of LV pre-A pressure, has been shown to be an important marker of adverse events in patients with preserved LV function. ${ }^{12}$ In the present study, we found that an E/Ea ratio $>13.8$ identified a subset of patients with AS at greater risk of future events.

1. Rahimtoola SH. Valvular heart disease: a perspective on the asymptomatic patient with severe valvular aortic stenosis. Eur Heart $J$ 2008;29:1783-1790.

2. Otto CM. Valvular aortic stenosis: disease severity and timing of intervention. J Am Coll Cardiol 2006;47:2141-2151.

3. Bonow RO, Carabello BA, Kanu C, de Leon AC Jr, Faxon DP, Freed MD, Gaasch WH, Lytle BW, Nishimura RA, O'gara PT, O'Rourke RA, Otto CM, Shah PM, Shanewise JS, Smith SC Jr, Jacobs AK, Adams CD, Anderson JL, Antman EM, Faxon DP, Fuster V, Halperin JL, Hiratzka LF, Hunt SA, Lytle BW, Nishimura R, Page RL, Riegel B. ACC/AHA 2006 guidelines for the management of patients with valvular heart disease: a report of the American College of Cardiology/ American Heart Association Task Force on Practice Guidelines. Circulation 2006;114:e84-e231.

4. Vahanian A, Baumgartner H, Bax J, Butchart E, Dion R, Filippatos G, Flachskampf F, Hall R, Iung B, Kasprzak J, Nataf P, Tornos P, Torracca L, Wenink A. Guidelines on the management of valvular heart disease: the Task Force on the Management of Valvular Heart Disease of the European Society of Cardiology. Eur Heart J 2007;28: $230-168$.

5. Hachicha Z, Dumesnil JG, Bogaty P, Pibarot P. Paradoxical low-flow, low-gradient severe aortic stenosis despite preserved ejection fraction is associated with higher afterload and reduced survival. Circulation 2007; 115:2856-2864.

6. Tongue AG, Dumesnil JG, Laforest I, Theriault C, Durand LG, Pibarot P. Left ventricular longitudinal shortening in patients with aortic stenosis: relationship with symptomatic status. J Heart Valve Dis 2003; 12:142-149.

7. Weber M, Arnold R, Rau M, Elsaesser A, Brandt R, Mitrovic V, Hamm C. Relation of N-terminal pro B-type natriuretic peptide to progression of aortic valve disease. Eur Heart J 2005;26:1023-1030.

8. Lim P, Monin JL, Monchi M, Garot J, Pasquet A, Hittinger L, Vanoverschelde JL, Carayon A, Gueret P. Predictors of outcome in patients with severe aortic stenosis and normal left ventricular function: role of B-type natriuretic peptide. Eur Heart $J$ 2004;25: 2048-2053.

9. Gerber IL, Stewart RA, Legget ME, West TM, French RL, Sutton TM, Yandle TG, French JK, Richards AM, White HD. Increased plasma natriuretic peptide levels reflect symptom onset in aortic stenosis. Circulation 2003;107:1884-1890.

10. Gerber IL, Legget ME, West TM, Richards AM, Stewart RA. Usefulness of serial measurement of $\mathrm{N}$-terminal pro-brain natriuretic peptide 
plasma levels in asymptomatic patients with aortic stenosis to predict symptomatic deterioration. Am J Cardiol 2005;95:898-901.

11. Bergler-Klein J, Klaar U, Heger M, Rosenhek R, Mundigler G, Gabriel H, Binder T, Pacher R, Maurer G, Baumgartner H. Natriuretic peptides predict symptom-free survival and postoperative outcome in severe aortic stenosis. Circulation 2004;109:2302-2308.

12. Yu CM, Sanderson J. Tissue Doppler imaging: a new prognosticator for cardiovascular diseases. J Am Coll Cardiol 2007;49:1903-1914.

13. Skjaerpe T, Hegrenaes L, Hatle L. Noninvasive estimation of valve area in patients with aortic stenosis by Doppler ultrasound and twodimensional echocardiography. Circulation 1985;72:810-818.

14. Lancellotti P, Cosyns B, Piérard LA. Dynamic left ventricular dyssynchrony contributes to B-type natriuretic peptide release during exercise in patients with systolic heart failure. Europace 2008;10:496-501.

15. Rosenhek R, Binder T, Porenta G, Lang I, Christ G, Schemper M, Maurer G, Baumgartner H. Predictors of outcome in severe, asymptomatic aortic stenosis. N Engl J Med 2000;343:611-617.

16. Pellikka PA, Sarano ME, Nishimura RA, Malouf JF, Bailey KR, Scott CG, Barnes ME, Tajik AJ. Outcome of 622 adults with asymptomatic, hemodynamically significant aortic stenosis during prolonged followup. Circulation 2005;111:3290-3295.

17. Otto CM, Burwash IG, Legget ME, Munt BI, Fujioka M, Healy NL, Kraft CD, Miyake-Hull CY, Schwaegler RG. Prospective study of asymptomatic valvular aortic stenosis: clinical, echocardiographic, and exercise predictors of outcome. Circulation 1997;95:2262-2270.

18. Lancellotti P, Lebois F, Simon M, Tombeux C, Chauvel C, Pierard LA. Prognostic importance of quantitative exercise Doppler echocardiography in asymptomatic valvular aortic stenosis. Circulation 2005; 112:I377-I382.

19. Lund O, Erlandsen M, Dorup I, Emmertsen K, Flo C, Jensen FT. Predictable changes in left ventricular mass and function during ten years after valve replacement for aortic stenosis. J Heart Valve Dis 2004;13:357-368.

20. Dalsgaard M, Egstrup K, Wachtell K, Gerdts E, Cramariuc D, Kjaergaard $\mathrm{J}$, Hassager $\mathrm{C}$. Left atrial volume in patients with asymptomatic aortic valve stenosis (the Simvastatin and Ezetimibe in Aortic Stenosis study). Am J Cardiol 2008;101:1030-1034.

21. Hein S, Arnon E, Kostin S, Schönburg M, Elsässer A, Polyakova V, Bauer EP, Klövekorn WP, Schaper J. Progression from compensated hypertrophy to failure in the pressure-overloaded human heart: structural deterioration and compensatory mechanisms. Circulation 2003; 107:984-991.

22. Lafitte S, Perlant M, Reant P, Serri K, Douard H, DeMaria A, Roudaut R. Impact of impaired myocardial deformations on exercise tolerance and prognosis in patients with asymptomatic aortic stenosis. Eur $J$ Echocardiogr 2009;10:414-419.

23. Poulsen SH, Sogaard P, Nielsen-Kudsk JE, Egeblad H. Recovery of left ventricular systolic longitudinal strain after valve replacement in aortic stenosis and relation to natriuretic peptides. J Am Soc Echocardiogr 2007;20:877-884.

24. Das P, Rimington $\mathrm{H}$, Chambers J. Exercise testing to stratify risk in aortic stenosis. Eur Heart J 2005;26:1309-1313.

25. Monin JL, Lancellotti P, Monchi M, Lim P, Weiss E, Piérard L, Guéret P. Risk score for predicting outcome in patients with asymptomatic aortic stenosis. Circulation 2009;120:69-75.

26. Legget ME, Kuusisto J, Healy NL, Fujioka M, Schwaegler RG, Otto CM. Gender differences in left ventricular function at rest and with exercise in asymptomatic aortic stenosis. Am Heart J 1996; 131:94-100.

27. Christ M, Laule-Kilian K, Hochholzer W, Klima T, Breidthardt T, Perruchoud AP, Mueller C. Gender-specific risk stratification with B-type natriuretic peptide levels in patients with acute dyspnea: insights from the B-type natriuretic peptide for acute shortness of breath evaluation study. J Am Coll Cardiol 2006;48:1808-1812.

28. Rossi A, Tomaino M, Golia G, Anselmi M, Fucá G, Zardini P. Echocardiographic prediction of clinical outcome in medically treated patients with aortic stenosis. Am Heart J 2000;140:766-771.

29. Poh KK, Chan MY, Yang H, Yong QW, Chan YH, Ling LH. Prognostication of valvular aortic stenosis using tissue Doppler echocardiography: underappreciated importance of late diastolic mitral annular velocity. J Am Soc Echocardiogr 2008;21:475-481. 